\title{
Challenges and Solutions for Hanoi to Become a Smart City
}

\author{
Pham Trong Thuat \\ Architectural Faculty, Hanoi Architectural University, Hanoi, Vietnam
}

Email address:

thuatarch@yahoo.com, thuat@hau.edu.vn

\section{To cite this article:}

Pham Trong Thuat. Challenges and Solutions for Hanoi to Become a Smart City. Urban and Regional Planning.

Vol. 5, No. 1, 2020, pp. 11-14. doi: 10.11648/j.urp.20200501.12

Received: February 17, 2020; Accepted: March 2, 2020; Published: March 6, 2020

\begin{abstract}
Smart city is a city that contains creativity, using information technology, communication and other means to improve the quality of life, the efficiency of urban activities and services. The Vietnamese government is choosing smart development as the basic concept for Vietnam's urban growth as a way to promote economic development in a smart way to avoid the rapid and polluting industrialization path of a number of cities growing. Hanoi is one of the two mega city of Vietnam, on the rise, with rapid urbanization, capable of applying technology to economic development as well as the living environment. However, the downside of smart technology is information security, personal privacy, information leakage, difficult to overcome the consequences if a system error occurs on a large scale... Therefore, experience from the lesson of smart cities in the world, Hanoi needs to aim at smart cities that "easy to live" than cities using ICT in operation.
\end{abstract}

Keywords: Smart City, ICT, Sustainable Development, Big Data

\section{Introduction}

'Smart city' is slowly becoming a tempting concept and a goal for developing or developed cities all over the world. In Vietnam, in 2018, Prime Minister Nguyen Xuan Phuc approved the project of developing a smart city over the period of 2018-2025 and towards 2030. The goal of sustainable urban development in Vietnam is to increase green growth, sustainable development, exploitation and promotion of potentials and advantages, raising the efficiency of the use of resources, to make optimal use of resources, human resources and improve the quality of life [6]. Even though there were some disadvantages, the city has had policies to train ICT (information and communication technologies) experts, the first step towards information technology developments.

Hanoi currently has a population of nearly 8 million people, which makes the population density of 2,279 people $/ \mathrm{km}^{2}$, and almost 42,000 people $/ \mathrm{km}^{2}$ in central districts. This increase in population would soon lead to several infrastructure shortage, such as traffic jams, lack of schools, hospitals, power, waste processing, etc. Apart from the suburb outside the $2^{\text {nd }}$ ring motorway, the 4 central district have an old infrastructure that has not been innovated for a long period, which is not capable of keeping up with the usage of the current population. The need to build a smart city requires proper management as well as the convenience, safety for the people. Therefore, for Hanoi, in order to have a clear path towards a smart city, the least requirements must be met and proper preparation must be done by research and learning from other cities.

\section{Problem Setting}

Hanoi needs to research the organisation of other modern cities in the world as well as the information technology system in order to become an active and smart city. So how do we define a smart city. This term has recently been used on many discussion threads about smart city over the past few years. Almost every modern city wants to become this model. Civil manager and government are also claiming that they are heading towards a 'smart city' model. In the end of 2017, China is on its path towards developing over 500 smart cities. Japan's idea of "Society 5.0" with the combination of a digital government, e-Health and e-Education. Similar to that is "Digital Canada" and "Smart Nation 2050" of Singapore. However, there are some arising issues with 'smart cities' is that these cities will act as an economic leader, causing an 
imbalance in development, as well as challenges in population management and wage gap: China population has increased 330 million people over the past decade, $30 \%$ of the UK economy is based in London. The statistics also applies for the Bangkok in Thailand, Lima in Peru, Manila in Philippines or Seoul in South Korea. The idea of becoming an E-City is also mentioned on the city council website in Hanoi, involving investing in broadband infrastructure, smart cards, Ecommerce and portal based electronic service delivery, as free Wi-Fi city. Since 2017 and the launch of FPT's Smarter City challenge there has been an increase in calls from both academics, Hanoi government and businesses for creation of smart cities embedding ICT into city. These existing issues are a challenge for Hanoi - the city that is in its first phase of developing into a smart city. In order to have a clear path for Hanoi to develop into a smart city, these issues need to be thoroughly researched and evaluated, namely:

\subsection{Research and Visualization of the Smart City Development Framework}

The 3 typical smart cities on the world are New York, Singapore and San Francisco, and there are cities in China that is catching up such as Shenzhen, Beijing and Shanghai. Seoul, Korea is also developing in a fast speed as the population is learning how to utilize the information technology system as well as the latest technology, which is a vital element for a smart city as such.

In order for the concept of 'smart city' to be done, we have to face these challenges by developing resources, network system along with ICT system for government departments, infrastructures and the general population. The difference in developing and managing smart city can be demonstrated in many methods, and should we well distributed between the rights of the citizen and the general benefits of the city. A smart city need to be built on the foundation of the interaction between different application, with access for every citizen (Big Data). This interaction requires a proper and well-organized information system, on a large scale that strictly follow the same standard and qualifications, in order to be organized and well-developed at the same speed, which is the basic foundation of a smart city. The different between a smart city and a normal city is the interaction between its people and the ICT system as well as the government. In this scenario, smart city is a city that the local communities constantly update, adapt and creatively approach to the new technology. This concept ensures the participation of every citizen in the city as well as encourage them to take part in managing and making the city a better place.

\subsection{The Bad Effects of Smart City}

It is an undeniable fact those people would prefer a city that is 'easier to live' rather than 'smart city' as it is the final goal of any citizen nowadays. The 'smart' element is just essentially one of the most effective methods to create a good environment for the city. Therefore, information technology system citywide needs to be well-organized and well- distributed so that a friendlier, better environment for the citizen. The foundation for building a city is based on ICT application with the participation of open interactions between individuals, organizations, and the authorities. However, information related to personal, election, financial and other important information, will become an issue information control. Personal privacy would be an issue to consider, as big data companies are collecting user information through personal accounts, CCTV and navigation devices, etc. In Hanoi, there are a number of real estate corporations that have established big data centers to gather the demand and habit of individuals in areas such as finance, health, education, etc. in order to have a better approach towards their services and how they orientate their business. When cities become smarter through data connection, in a way, we face risks in the development process, when residents are dominated by their activities to a certain extent.

\section{Principles of Smart City for Hanoi}

\section{1. 'Unwrapping' the Smart City Label}

Hanoi has the advantage of having a relatively young population compared to other Asian cities, who has access to technology, willing to play an important role in the future to build a smart city through the application of smart technology. Referring to smart city, it is commonly known that Danang is one of the five typical cities in the process of developing smart city. Danang is Vietnam's fourth largest city and has been experiencing rapid growth in recent years. By 2020, the city will deploy traffic monitoring tools to reduce congestion by monitoring traffic signals throughout the city in real time, according to a report by Nikkei Asian Review. In addition, the city plans to upgrade the technology for managing greenery in coastal areas within the same time frame. Danang has become a technology center of the Central region, attracting young talents to work for newly established companies, especially technology companies in general and information technology in particular. With ambition to become a typical small urban sustainable development in the future.

Through the example of Danang, we can see a version of Hanoi to develop by 2030 - a vision of 2050 in the direction of Green - Cultural - Civilized - Modern with highlights showing the depth of culture and history and urban memories, while catching up with the trend of globalization, integration with the world is a relatively challenging task. In fact, Hanoi is dominated by the development of an increasingly complex real estate market, with the emergence of high-rise condominiums inside the $2^{\text {nd }}$ ring motorway and a lack of uniformity in infrastructure. For real estate investors, it may be a smart investment in terms of business, but not smart in terms of a sustainable urban development. In addition, the increase in the number of motorized vehicles, especially personal vehicles, will make the problem of traffic congestion much more complicated. The city government should aim at the nature of a smart city, which is to balance 
the interests of the community with the common goal of the city on the basis of using ICT infrastructure.

The final goal is to improve management efficiency, create a favorable environment for synchronous economic, social, cultural and environmental development. These elements are vital to the optimization of transportation services, business services, housing and other types of public services. Furthermore, the city government must control the saving of urban resources, which is a prerequisite to ensure sustainable urban development. ICT system should also be considered a vital tool, helping in manage and get an overview before coming up with suitable methods for urban developing.

\subsection{Smart Information technology System}

The ICT system determines the success of smart city development, formed on the foundation of the interaction between branches of specialized management area of the city, in order to create an ecology system ensure the sustainable development of urban public services. Hanoi population of nearly 8 million in 2018, with 9.82 million mobile phone users- mostly smart phones [13]. Urban population with over 80 per cent of the population connected to the internet (not to mention its clustering of numerous software firms) [13]. The rapid spread of telecommunications technology allows the integration, analysis and use of data of urban residents in all areas of daily life, serving for the planning of urban development planning. The problem is that there must be effective filtering tools for information to be formed constantly, developing at the same time with the general speed of urban development. These data should be transparent and accurate to ensure the feasibility of development plans, as well as to the well-being of the city in a sustainable development.

\subsection{Smart Transportation}

The trend of smart urban development of San Francisco, Singapore or Tokyo allows us to understand the importance of public transport infrastructure as well as the control system to meet the increasing demand in general transportation is a solution of reducing traffic congestion. On the other hand, it is also a solution help to reduce the working hours of the citizen that is caused by traffic congestion. There are some big cities have a large traffic transport data system in Vietnam: Hanoi, Danang, Cantho, Ho Chi Minh city etc. As others cities, in Hanoi, the data generated by transport systems can also help to optimize the movement of goods. Information from CCTV system, survey, measurement, vehicle statistics, frequency and transport-related attributes for urban districts, each route will help to optimize the ability to utilize the urban transport system. Furthermore, the city government needs to have long-term solutions for the people, for instance, reducing personal transportation by encouraging people to use public transport. Therefore, it is necessary to have synchronous solutions to organize the subway system in the future, electric trains, buses, etc. in order to create the convenience and necessary trust with the people.

\subsection{Smart Management}

Smart cities are cities that are able to optimize and balance its processes and infrastructures through the ICT system. However, this does not define the "smartness" of other cities. This concept refers only to cities through the effort in management and coordinating components to improve people's life quality, such as improving the effectiveness of public services and counter-measurements and responding time to emergencies and natural disasters, being able to quickly improvise everywhere in the inner boundaries of urban areas, to access information and process information in a timely manner. Asian cities such as Singapore, Tokyo, Soul or some of China's major cities are somewhat "smart", thanks to the investment policies and management for urban transport solutions including static traffic, motorized trasortation and other urban technical infrastructure. The trend of connecting handheld devices, CCTV systems with V2X technology will be a factor to promote the process of building, operating and managing smart urban areas.

In addition, smart management analysis can help the Hanoi government build and implement a satisfactory democratic policy, as they have become acquainted with the needs of people in the areas of health care, social aid, education, etc. Hanoi with a young population, social housing and public service issues will be the areas that benefit from smart management. In addition, the unemployment rate can also be reduced by the intelligent management analysis method of various educational institutions.

\section{Conclution: Toward Sustainable Development}

Many cities all around the world wants to acquire the title of "smart city" with the purpose of empowering the city and its country. Therefore, the strategy of achieving the criteria of an intelligent metropolis are being chosen by many city governments. However, Hanoi in particular and Vietnam's urban areas in general, need a comprehensive and an organized approach to achieve this goal. The time period to achieve the title of smart city might be longer, but the preparations to ensure the having ability a sustainable development is needed and should be prioritized. It is also a smart choice for cities in this development path not just to adopt advanced information infrastructure as 'smart city' is not only a wi-fi system and smart handsets, smart offices, trendy luxury apartments and luxury hotels. Becoming a smart city in a rush would come with many risks of information security, operational risks of the city management, risks in solving citizen rights and equality, therefore, Hanoi needs a synchronous approach to ensure the future of a sustainable city. 


\section{References}

[1] G I Kurcheeva, G A Klochkov (2018). Comprehensive approach to smart urban development based on Big Data application.

[2] Graham, S. and Marvin, S. (1996) Telecommunications and the City. London: Routledge.

[3] Hollands, R. G. (2008). Will the real smart city please stand up? Intelligent, progressive or entrepreneurial.

[4] Milan Husar, Vladimir Ondrejieka, Sila Varis (2008). Smart Cities and the Idea of Smartness in Urban Development - A Critical Review.

[5] Robert G Hollands, (2008). Will the real smart city please stand up? Intelligent, progressive or entrepreneurial.

[6] Wirawan Agahari, Dinita Andriani Putri, (2011), From smart city to open city: Lessons from Jakarta smart city.

[7] Faris Dzulfikar, Dinda Dewinta, (2015). A city with smart energy managament for economic development in Asean.

[8] Pham Trong Thuat, (2019). Symbiotic ralations between people and urban authotities to develop smart cities.

[9] Phuong Hao, (2019).Big expections for Vietnam in sustainable smart city development

[10] Phong Lan, (2019). New drive in smart city development

[11] Gregory Kovacs, Huynh Xuan Thu, Kim Yoon Young (2019), The road to smart ciites in Vietnam

[12] Ayyoob Sharifi, (2020). Urban sustainability assessment tools: toward integrating smart city indicators

[13] Thủ tướng phê duyệt Đề án phát triển đô thị thông minh (2018). http://cafef.vn/thu-tuong-phe-duyet-de-an-phat-triendo-thi-thong-minh-201808022120236.chn.

[14] Vietnam Population ( 2018). http://danso.org.

[15] Việt Nam đã có bao nhiêu thuê bao di động? (2018). https://baomoi.com/viet-nam-da-co-bao-nhieu-thue-bao-didong/c/26818355.epi. 